Brit. J. vener. Dis. (1956), 32, 246.

\title{
FURACIN URETHRAL SUPPOSITORIES IN THE TREATMENT OF CHRONIC NON-GONOCOCCAL URETHRITIS*
}

\author{
BY \\ R. R. WILLCOX \\ St. Mary's Hospital, London
}

Furacin urethral suppositories $\nmid$ (containing nitrofurazone 0.2 per cent. and 2 per cent. diperodon hydrochloride (N.N.R.) a local anaesthetic, dissolved in a water-dispersible base composed of glyceryl monolaurate and sorethytan (4) monostearate (Tween 61) are available for the treatment of non-gonorrhoeal, bacterial (granular) urethritis of women, a condition not generally recognized in Great Britain. They are yellowish, soft pessaries of $1.3 \mathrm{~g}$. each, wrapped in foil and intended to melt at body temperature. The suppositories are slightly tapered, being 2.5 in. long and 0.2 in. in diameter at the wider end.

Their use in chronic non-gonococcal urethritis in males has been investigated, as the pessaries might provide an alternative to urethral irrigations which are still used in those cases which have repeatedly failed to respond to antibiotics. If successful, they would be welcomed by venereologists in private practice, since urethral irrigations are often difficult to arrange, because of the small present-day demand for them. An alternative local treatment which can safely and effectively be undertaken by the patient offers significant administrative advantages.

\section{Material and Method}

Sixteen male patients with non-gonococcal urethritis were treated with the suppositories, and two relapses were re-treated, making eighteen cases in all. Eight men were single, seven were married, and one was divorced. Their average age was $36 \cdot 9$ years (range 25 to 55 ), which is higher than the usual age of patients with this condition in previously reported series. In most instances, the disease was chronic, often very markedly so, the discharge having been present for one month or less in only three, for 2-3 months in five, for 4-6 months in two, for 7-11 months in one, and off and on for a year or more in four patients. In one case, the duration was uncertain, but was probably long. In two patients, trichomonads were found before treatment.

* Received for publication September 11, 1956.

+ Manufactured by Eaton Laboratories Inc.
In all cases, the pessaries were used twice daily. As each bottle contained twelve pessaries, a week's treatment meant in practice only 6 days, with no treatment on the seventh day. Twelve pessaries or less were used by six patients, 24 by three, 36 by two, 48 by one, sixty by three, and 72 by one.

The case histories are given below in detail and the results are summarized in the Table.

\section{TABLE}

SUMMARY OF RESULTS WITH FURACIN URETHRAL SUPPOSITORIES IN SIXTEEN PATIENTS

\begin{tabular}{|c|c|c|c|c|c|}
\hline $\begin{array}{l}\text { Case } \\
\text { No. }\end{array}$ & $\begin{array}{l}\text { Type of } \\
\text { Urethritis }\end{array}$ & $\begin{array}{c}\text { No. } \\
\text { of } \\
\text { Pes- } \\
\text { saries }\end{array}$ & $\begin{array}{l}\text { Immediate } \\
\text { Result }\end{array}$ & Ultimate Result & $\begin{array}{c}\text { Liking } \\
\text { for } \\
\text { Pessaries } \\
\text { by } \\
\text { Patient }\end{array}$ \\
\hline 1 & Chronic & 48 & Success & $\begin{array}{l}\text { Recurrence at } 5 \\
\text { months }\end{array}$ & Yes \\
\hline 2 & Subacute & 24 & Success & $\begin{array}{l}\text { Satisfactory at } 206 \\
\text { days }\end{array}$ & Yes \\
\hline 3 & Chronic & 60 & Improved & $\begin{array}{l}\text { Relapse within } 3 \\
\text { weeks }\end{array}$ & Yes \\
\hline 4 & Chronic & 60 & $\begin{array}{l}\text { Slow im- } \\
\text { provement }\end{array}$ & $\begin{array}{l}\text { Recurrence at } 5 \\
\text { months }\end{array}$ & Yes \\
\hline 5 & Chronic & 36 & Failure & - & Yes \\
\hline 6 & Subacute & 12 & Improved & $\begin{array}{l}\text { Relapse within } 2 \\
\text { weeks }\end{array}$ & No \\
\hline 7 & Chronic & 8 & Success & $\begin{array}{l}\text { Satisfactory at } 21 \\
\text { days }\end{array}$ & No \\
\hline 8 & Chronic & 12 & Failure & 一 & No \\
\hline 9 & Chronic & 4 & Improved & $\begin{array}{l}\text { Recurrence within } \\
4 \text { weeks }\end{array}$ & No \\
\hline 10 & Chronic & 12 & Failure & - & No \\
\hline 11 & Chronic & 24 & Success & $\begin{array}{l}\text { Satisfactory at } 42 \\
\text { days. }\end{array}$ & Yes \\
\hline 12 & Subacute & 12 & Failure & - & No \\
\hline 13 & Subacute & 24 & Success & $\begin{array}{l}\text { Satisfactory at } 20 \\
\text { days }\end{array}$ & Yes \\
\hline 14 & T. & 36 & ?Success & $\begin{array}{l}\text { Impossible to } \\
\text { assess }\end{array}$ & Yes \\
\hline 15 & $T$ vaginalis & $\begin{array}{l}24 \\
36\end{array}$ & $\begin{array}{l}\text { Success } \\
\text { Success }\end{array}$ & $\begin{array}{l}\text { Relapse at } 9 \text { weeks } \\
\text { Satisfactory at } 8 \\
\text { weeks }\end{array}$ & Yes \\
\hline 16 & Chronic & $\begin{array}{l}36 \\
36\end{array}$ & $\begin{array}{l}\text { Success } \\
\text { Success }\end{array}$ & $\begin{array}{l}\text { Relapse at } 7 \text { weeks } \\
\text { Satisfactory at } 2 \\
\text { weeks } \\
\text { Relapse at } 3 \text { weeks }\end{array}$ & Yes \\
\hline
\end{tabular}




\section{Case Histories}

In the case histories which follow, it may be assumed, unless otherwise stated, that the urethral smears contained no gonococci, that the Wassermann, Kahn, or VDRL, and the gonococcal complement-fixation tests were negative; and that no trichomonads were found by dark field examination.

Case 1, a married business man aged 48, who had frequent extra-marital intercourse with the same girl. When first seen in October, 1954, he had had a urethral discharge since August 28. There had been no previous venereal disease. Treatment with penicillin, sulphonamides, and chloromycetin had been unsuccessful. The consort was under treatment for trichomonal vaginitis, but no trichomonads were found in the urethral discharge of the patient. He was treated with oxytetracycline $250 \mathrm{mg}$. four times a day and had $22 \mathrm{~g}$. in all. This cleared the discharge, but on October 29 there was a relapse which was treated with erythromycin-total $9.6 \mathrm{~g}$. over 8 days. After an initial improvement, the discharge again relapsed and he was then given Furacin urethral suppositories. Four bottles (48 suppositories) were used, at first twice daily for 3 weeks, and then once daily. Towards the end of this period, he complained of some urethral irritation which disappeared once the treatment had been stopped. Response was good, and the discharge slowly cleared. 5 months later, he was successfully treated with tetracycline for a further attack but he had remained well in the interval.

Chronic urethritis: Success? Later re-infection.

Case 2, a painter aged 38 (married 9 years) with intrameatal hypospadias. In 1950 he had four attacks of cystitis and an attack of non-gonococcal urethritis which responded to streptomycin but later relapsed. He had radiographic investigations with negative results and was treated with penicillin. There was a further attack in 1951, which cleared with oxytetracycline, and he was discharged in July of that year.

In December, 1954, he had a further attack. There was no improvement after $6.0 \mathrm{~g}$. erythromycin given for a period of 5 days, and Furacin urethral suppositories were then used twice daily for 2 weeks. All signs had disappeared after the first week and the patient remained satisfactory at examinations made at $13,36,69$, and 206 days from the onset of treatment with suppositories. Subacute urethritis: Responded.

Case 3, a neurotic married physician aged $\mathbf{5 5}$, also with hypospadias. He was first seen in June, 1950, with a chronic urethritis of some years' duration. Complete urinary investigations, including radiography, gave negative results. He was treated with penicillin and streptomycin, with some improvement. In September, 1950, he was again complaining of a milky discharge and was given chlortetracycline, and later Benadryl. He left for the Far East in December, 1950.

He was seen again in July, 1954, having had in the meantime, several treatments with chlortetracycline and oxytetracycline. There was no evidence of urethral stricture, and more oxytetracycline was given. In December, 1954, a purulent discharge was still present, and oxytetracycline was again given but without obvious result. On December 23, he started using Furacin urethral suppositories, one twice daily and these were continued for 5 weeks. Immediate improvement was noted, pus was no longer present in the urethral smears, and the urine cleared. On February 14, 1955, however, less than 3 weeks after completion, but 53 days from commencement of treatment with suppositories, the discharge re-appeared as before. He left for overseas in April, 1955, the condition being largely unchanged. Chronic urethritis: Immediate improvement. Relapse.

Case 4, a labourer aged 37, single, also suffering from psoriasis. When first seen in July, 1947, he complained of a urethral discharge of 2 days' duration; there was no previous history of venereal disorders. He was treated with sulphadiazine and with penicillin, but the condition did not clear completely. In 1948, he again received both of these drugs although he was under observation mainly for psoriasis. He was discharged in November, 1948, but returned in 1950 for further treatment for psoriasis and chronic urethritis. Streptomycin and three courses of chloramphenicol were given during 1950; chlortetracycline, oxytetracycline, penicillin, chloramphenicol, and streptomycin were given during 1951 ; and further treatment with chloramphenicol was given during 1952. Oxytetracycline ointment was injected into the urethra on several occasions with improvement, and all treatment was stopped in September, 1952. In April, 1953, however, there was a further relapse which was treated with oxytetracycline, sulphadiazine, and oxytetracycline. By this time, both patient and physician had come to regard the residual urethritis as incurable, and throughout 1954 attention was directed towards the psoriasis rather than to the urethritis.

Beginning in November, 1954, Furacin suppositories (which were now available) were used night and morning, for 5 weeks. The discharge dried up after 48 suppositories had been used and the patient then defaulted. He returned in April, 1955, 5 months after commencing treatment with Furacin, with the discharge present as before.

Chronic urethritis: Initial response followed by relapse (or re-infection).

Case 5, a fitter aged 27, married for 18 months. He was first seen in November, 1954, with non-gonococcal urethritis. There had been a previous attack one year earlier for which oxytetracycline, urethral irrigations, streptomycin, and more oxytetracycline had been required. He was given erythromycin $200 \mathrm{mg}$. four times daily for 5 days. In January, 1955, he had a return of a mild urethritis, with urethral moisture. Treatment with Furacin urethral suppositories given twice daily was commenced on January 31 , and continued until three bottles had been used in 3 weeks. On February 26, however, the urethra was still moist, and pus was still present in the urethral smear. This cleared with tetracycline administered orally.

Mild chronic urethritis: Failure.

Case 6, a salesman, aged 38, married 15 years. He first attended on February 9, 1955, suffering from nongonococcal urethritis of 6 days' duration, having had intercourse with a prostitute 2 weeks earlier. There was a history of a previous attack of non-gonococcal urethritis, treated at another clinic, from August to November, 1954, with irrigations, sulphonamides, streptomycin, and oxytetracycline. He was given tetracycline $1 \mathrm{~g}$. daily for 6 days. After an initial improvement, pus was found in the urethral smear on February 23 and he was given Furacin urethral suppositories twice daily for one week. The patient returned on March 9, when he reported that there had been an initial improvement, followed by relapse. He did not like using the pessaries, however, as they did not dissolve well, and the 
improvement was not maintained. The condition cleared with more tetracycline.

Subacute urethritis: Initial improvement but pessaries not liked by the patient.

Case 7, a waiter, aged 29, single. He had had repeated, and often prolonged, attacks of non-gonococcal urethritis in 1941, March-May, 1952, July-September, 1952, November, 1952, December, 1952-January, 1953, September, 1953, and December, 1954. He returned on March 15, 1955, complaining of a morning discharge and dysuria. No discharge was evident and the urine was clear. He was given a slide to collect a specimen of the discharge. The slide showed pus, and on March 17, 1955, he was given Furacin urethral suppositories twice daily for a week. After using eight, he complained of dysuria, and said that he could not manage the pessaries. The urine was clear but he was given potassium citrate. After 7, 14, and 21 days from the onset of treatment, he had remained well. He last attended in April, 1955.

Chronic urethritis: Apparent success.

Case 8, a clerk, aged 35, single. He had had gonorrhoea in 1951, and again in May, 1954; he had also had nongonococcal urethritis "after swimming" in 1950, and further attacks in November, 1954, and June, 1955. In August, 1955, he was still complaining of a yellowish discharge in the mornings, which contained pus; the urine showed a haze. He was treated with sulphadiazine and streptomycin with improvement but by the end of the month the morning discharge (perhaps aggravated by manual squeezing) was still apparent. He was given Furacin urethral suppositories twice daily for one week. A week later, he reported that the pessaries did not dissolve, and that they were painful to use. His discharge finally cleared after tetracycline given in October, 1955, and he remained well until last seen in May, 1956.

Chronic urethritis: Failure. Pessaries not liked by patient.

Case 9, a press operator, aged 26, single and promiscuous. He was seen on March 12, 1955, during a first attack of non-gonococcal urethritis. He was given penicillin and then oxytetracycline with success. His condition had relapsed on April 25, and he was treated with tetracycline and penicillin. There was a further recurrence on June 20,1956, when Furacin pessaries, one twice daily, were prescribed. He used only four as he four d them difficult to manage, but nevertheless the dischar ze cleared. He was seen again on July 18, 1955, with a fi sther discharge (? re-infection) when more tetracycline was given.

Recurrent chronic urethritis: Result difficult to assess. Pessaries apparently helped but not liked by patient.

Case 10, a carpenter, aged 31, single. He was first treated for non-gonococcal urethritis in 1950 . He complained of a mucous discharge in July, 1955, when nothing was found. An early morning smear, taken on September 3, 1955, however, showed pus. For the next 2 months he was given chlortetracycline, penicillin, erythromycin, and sulphadiazine, and during the last 6-8 weeks of the year he was apparently well. In early January, 1956, he complained again of a mucoid discharge in the morning. On January 14 he was given Furacin urethral pessaries, one twice daily, but when seen a week later he stated that he could not retain them. The patient continued to complain about the discharge until he defaulted in June, 1956.

Chronic mild urethritis: Failure. Pessaries not liked by patient.
Case 11, a storekeeper, aged 53, divorced. He suffered from a chronic anxiety state, and was said to have had a urethral stricture in 1940, but there is considerable doubt about this. The patient complained of continual pains in the penis, and an early morning discharge after a mild attack of non-gonococcal urethritis, treated with oxytetracycline, in September, 1955. He had made twelve more visits to hospital by February 22, 1956, during which time little was found although he was given an occasional urethral irrigation as a placebo. Some pus was then again found in the early morning smear, and he was given a further course of oxytetracycline which apparently cleared it. At this time he got married and his anxiety and complaints intensified. He made seven more visits by June 14, during which time urethroscopy was performed, with negative results. At this date, he was again complaining of an early morning discharge which contained pus. On June 21, he was given Furacin urethral suppositories, which he used for 2 weeks. The results were prompt; at the end of the first week, he stated that he had been completely dry for three mornings, and both he and the physician were much happier. His status was completely satisfactory at $7,14,28,35$, and 42 days from the time when he started using the pessaries.

Chronic mild urethritis: Success.

Case 12, a white West Indian dancer, aged 34, single. He was first seen with non-gonococcal urethritis of one week's duration after casual exposures 2 and 21 days previously. He was treated with streptomycin and sulphadiazine commencing on June 19, 1956. On June 28 he stated that he was no better and he was given Furacin urethral pessaries one twice daily. On July 5 the urethral smear still contained pus, and threads were seen in the urine. His condition was not improved by the pessaries, and he was given tetracycline orally instead. He did not return.

Subacute urethritis: Failure.

Case 13, a Negro stone mason, aged 25, from Granada, single. He was treated on April 27, 1956, for acute gonorrhoea. This was followed by a complaint of local irritation but nothing definite was found at seven intermediate visits until June 18, 1956, when he was found to have mild non-gonococcal urethritis, which was treated with a 5-day course of oxytetracycline, without improvement. On June 28, 1956, he was given Furacin urethral suppositories one twice daily for 2 weeks. Improvement was noted at the end of this period and 13 and 20 days after starting Furacin the prostatic secretion was free from pus, and the urine free from threads.

Subacute urethritis: Success.

Case 14, a business man, aged 46, married. He was first seen on March 23, 1956, because his wife had a chronic recurring trichomonal vaginitis. He made no complaints but the urine contained threads, the right side of the prostate was enlarged, and the prostatic secretion contained much pus and many trichomonads. The patient was given erythromycin $200 \mathrm{mg}$. four times for 6 days. At the end of this time, he had a profuse urethral discharge containing trichomonads and pus, and also Gram-negative diplococci. He was given penicillin, tetracycline, and a week's treatment with Furacin urethral suppositories. Seen again on April 21, 1956, there was still some discharge containing pus but no trichomonads were seen. A further penicillin injection was given and he was asked to continue with the pessaries. He subsequently went overseas.

Trichomonal urethritis: Impossible to assess as too many forms of treatment were given concurrently. 
Case 15, a West Indian porter, aged 37, single. He first attended on October 19, 1955, with non-gonococcal urethritis, having had intercourse with a stranger 2 weeks' before. Trichomonads and non-specific spirochaetes were found. There had been an attack of gonorrhoea 5 years previously. He was given $4 \mathrm{~g}$. oxytetracycline in 4 days, at the end of which time trichomonads were still present. He was subsequently given methylene blue instillations, and the discharge slowly subsided. He was seen on November 14, 1955, with no discharge and clear urine but no further tests for trichomonads had apparently been made in the meantime. He then defaulted.

The patient attended again on April 21, 1956, suffering from non-gonococcal urethritis, and was given an injection of streptomycin. On April 25, trichomonads were easily demonstrable, and he was given mepacrine orally, $0.2 \mathrm{~g}$. three times a day for 7 days but the discharge was still present and parasites still demonstrable at the end of that time. On May 2, 1956, he was given Furacin urethral pessaries, one twice daily for 2 weeks. The urethral discharge subsided during the first week, and the threads disappeared from the urine. Tests for trichomonads were negative $7,21,49$, and 56 days from the commencement of treatment. At 63 days, however, the discharge and threads in the urine recurred, and trichomonads were again present. He denied re-exposure.

The relapse was treated with Furacin urethral suppositories one twice daily for 3 weeks without other measures.

The discharge disappeared within a few days and the trichomonads could no longer be found on the seventh day. The threads had largely disappeared from the urine but a few specks remained. At the 14th, 28th, and 56th days, the urine was quite clear, and the dark-field test from a urethral scraping showed no trichomonads.

Chronic trichomonal urethritis: Success with relapse and subsequent successful treatment of relapse.

Case 16, an inspector, aged 31, married for one year, who had been treated in 1947 for non-gonococcal urethritis. On March 5, 1956, he complained of painful erections for 2 months, and a moderately profuse urethral discharge was present. No trichomonads were found. The urethritis did not respond to oxytetracycline, repeated injections of procaine penicillin with aluminium monostearate, and a course of erythromycin. Although there had been temporary periods of partial improvement, the purulent urethral discharge was still present on May 5, 1956, when he was given Furacin urethral suppositories one twice daily for 3 weeks. These were successful in removing the chronic discharge, and he was found to be well at visits made 7,14 , and 28 days from the commencement of Furacin treatment. On June 23, however, the discharge had relapsed as before.

The patient was then given a 6-g. course of tetracycline in 6 days, and the condition improved. On July 7, a bougie was passed which showed no obstruction, and prostatic examination was normal. Shortly afterwards, the discharge recurred. He then commenced a course of Furacin urethral suppositories one twice daily for 3 weeks and immediate improvement followed. At the end of one week, there was no discharge and the urine was clear. After 2 weeks there was still no discharge but the urine was slightly hazy. He relapsed a week later but responded again to Furacin.

Relapse of chronic urethritis: Initial success followed by relapse. Relapse responded initially to re-treatment.

\section{Results}

Immediate Results.-Immediate improvement was noted by twelve patients ( 75 per cent.), and not noted by four. The two cases with trichomonal urethritis improved, as did three of four cases of sub-acute urethritis, and seven of ten cases of chronic urethritis.

Of the four immediate failures, three patients disliked the pessaries and had used them for only one week, and in one patient 36 pessaries had been administered. Immediate improvement was again noted in two patients who were re-treated with the pessaries.

Ultimate Results.-Of the twelve patients showing immediate improvement, the condition of four remained satisfactory after observation periods of 20 days, 21 days, 42 days, and 206 days, respectively, and the two patients who were re-treated also responded initially. In one case, it was not possible to assess the ultimate result. Recurrences, were noted however, in the other seven: within 2 weeks in one, within 3 weeks in one, within 4 weeks in one, within 7 weeks in one, within 9 weeks in one, and within 5 months in two. It was not possible to state whether these recurrences were due to relapse or re-infection.

Trichomonal urethritis.-Two patients had trichomonal urethritis, which is usually a very obstinate condition in the male. In one, there was an immediate response but it was not possible to assess the ultimate result. In the other, there was a striking initial success, and no recurrence was noted until 9 weeks had elapsed, when trichomonads were again found. The response of the recurrence to re-treatment was equally striking.

\section{Tolerance of Pessaries}

In two patients mild reactions were noted. In one (Case 1), there was urethral irritation during the fourth week of treatment and the other (Case 7) complained of dysuria after using only eight pessaries.

Ten patients liked the pessaries, and six did not. In the main, the principal complaint was that the pessaries did not dissolve easily, and certainly not completely. They felt, therefore, that the treatment could not be successful in these circumstances. In general, the better educated the patient, the better was he able to manage the treatment.

\section{Summary and Conclusions}

(1) Sixteen male patients with non-gonococcal urethritis were treated with Furacin urethral suppositories one twice daily for varying periods of time. In most instances the disease was chronic, often markedly so. The Furacin suppositories were also used in the re-treatment of two cases. 
(2) There was an immediate improvement in twelve patients (75 per cent.),. including two with trichomonal urethritis. In seven of these cases, however, the urethritis was known to recur after intervals of up to 5 months. It is not known whether these recurrences were due to relapse or re-infection. Response was noted in both patients who were re-treated.

(3) Over 500 pessaries were used in these trials, and only two patients had any untoward reaction to them, one of irritation, and one of dysuria; both reactions were minor.

(4) The cases reported in this series were mainly the most difficult encountered in present-day venereology. The majority had long histories of recurrent trouble, which had resisted treatment with many modern antibiotics. The high ultimate recurrence rate, therefore, should not imply too great a criticism of the pessaries.

(5) The pessaries succeeded, at least temporarily, in making the urethra dry in $\mathbf{7 5}$ per cent. of cases- an achievement equalled by routine urethral irrigations. Moreover, the treatment was undertaken at home with no trouble to the doctor and with considerably less inconvenience to the patient than if irrigations had been used.

(6) The success of Furacin suppositories in trichomonal urethritis, a very obstinate condition in the male, is noted. It may well become the treatment of choice.

(7) While no strong curative claims can be made for local Furacin treatment, it is undoubtedly capable of suppressing the residual symptoms in chronic urethritis which has proved resistant to other measures. For this reason, it is considered that these pessaries have a definite and useful role in the management of chronic urethritis.

Grateful acknowledgements are expressed to Messrs. Menley and James Ltd., of London, for kindly supplying the Furacin urethral suppositories used in this study. 